\title{
DERLEME
}

\section{DOĞUM AĞRISINDA KULLANILAN TAMAMLAYICI TEDAVİ YÖNTEMLERİ}

\author{
Zümrüt YILAR ERKEK *
}

\author{
Türkan PASÍNLİĞLUU**
}

Alınıș Tarihi: 12.11 .2015

Kabul Tarihi: 22.02 .2016

\begin{abstract}
$\ddot{O} Z E T$
Doğum ă̆rısl, anneyi mekanik olarak yoran, stres ve anksiyeteye neden olan hiperventilasyon ile oksijen ihtiyacını arttıran bir olaydır. A ̆grı ile mücadelede başarısız olunmasi; annenin tükenmesine sebep olarak, anne bebek etkileşimini zorlaştırmakta, doğum eyleminden alınacak mutluluğu engellemekte, doğum sonu konforu azaltmakta ve annenin diğer doğumlara yönelik tepkisini olumsuz yönde etkileyebilmektedir. Bu durum, doğum ağrısının kabul edilebilir veya gerekli olduğu düşüncelerini ortadan kaldırmış ve doğum ağrısının varlığı tedavi için bir endikasyon olarak kabul edilmiştir. Bu nedenle doğumu ă̆rıdan bağımsız kılmak amacıyla çok fazla yol denenmiştir. Fakat doğum ăgrısının azaltılmasındaki ilerlemelere karşın, ăgrı kadınların tamamında belirgin olarak yönetilememiştir. Bu durum hem kadınları hem de bakım verenleri ağrının yönetiminde farklı arayışlara yönlendirmiştir. Bu amaç doğrultusunda Tamamlayıcı Tedavi yöntemleri kadınların ve sağllk profesyonellerinin son zamanlarda doğum ăgrisiyla baş etmelerinde çok fazla tercih edilir duruma gelmiştir.

Bu derlemede konu ile ilgili kaynaklar taranarak doğum ağrısını hafifletmek amacıyla en sık kullanılan Tamamlayıcı Tedavi yöntemlerine yönelik sağlık çalışanları başta olmak üzere tüm bireylere bakış sağlamak amaçlanmıştır.
\end{abstract}

Anahtar Kelimeler: Tamamlayıcı tedavi yöntemleri; doğum ăgrısı; ebe/hemşire

ABSTRACT

Complementary Treatment Methods Used for Labor Pain

Labor pain is an event that tires the mother mechanically, causes stress and anxiety, and increases the need for oxygen by hyperventilation. Failure at the competition with pain could complicate the mother-infant interaction, decrease or prevent the pleasure generated by giving birth, and decrease comfort levels after the labor and delivery. Labor pain can exhaust the mother and make her fear future labors. Thus, labor pain needs to be addressed, and many treatment methods have been tried.However, labor pain is not managed to a significant degree in all women.Thus, many mothers and health care workers have sought alternative medicine approaches for labor pain management, and many women and health care workers prefer such Complementary Treatment methods.

This review was prepared to provide especially healthcare workers to all individuals a description of the most frequently used Complementary Medicine treatment methods by making a literature review about complementary treatment methods that are used for the management of labor pain.

Key Words: Complementary Treatment Methods; Labor Pain; Nursing/Midwifery

\section{GíRiș}

Tamamlayıcı Tedavi Yöntemleri (TTY) "çağdaş tıp bilimince hastalık sebeplerini önlemede kanıtlanmış bir tedavi yöntemi olmadığı halde; bireyin isteğiyle çağdaş tıp tedavilerinin yanında, onlara destekleyici olarak bireyin rahatlaması, bağışıklık sisteminin güçlenmesi, psikolojisinin düzelmesi gibi amaçlarla uygulanabilen alternatif tıp yöntemleridir." $\mathrm{Bu}$ yöntemler modern tıp biliminde hastallk sebeplerini önlemede somut verilerin olmadığı veya kanıtlanmış bir tedavi yöntemi olmadığı durumlarda kullanılmaktadır (Bulduklu 2015).

Gelişmiş ve gelişmekte olan birçok ülkede TTY'ne olan ilgi ve toplumdaki kullanım sıklığ1 giderek artış göstermektedir. Üreme çağındaki kadınların yaklaşık \%49'u TTY'ni yaygın olarak kullanmaktadır (Smith, Collins, Cyna and Crowther 2010). Kanser başta olmak üzere astım, romatoid artrit, inflamatuar barsak hastalıkları ve karaciğer hastalıkları, multiple sklerozis, böbrek yetmezliği, hipertansiyon gibi kronik hastalıklar, alerjik hastalıklar, kistik fibrozis, ağrı, anksiyete, depresyon ve yorgunluk gibi durumlarda hastalar TTY'ni kullanmaktadır. Bu kadar geniş bir kullanım alanına sahip olmalarından dolayı,

\footnotetext{
* Yrd.Doç.Dr, Gaziosmanpaşa Üniversitesi Sağlık Yüksekokulu, Ebelik Bölümü, e-posta: zyilar@ hotmail.com ** Prof.Dr., Atatürk Üniversitesi Sağlık Bilimleri Fakültesi-Erzurum
} 
sağlık bakım kurumlarında tamamlayıcı tedaviler hasta bakım hizmetlerine dahil edilmektedir (Set 2011; Turan, Öztürk ve Kaya 2010). Bu doğrultuda derlemede doğum ağrısında tercih edilen TTY'ne yönelik tüm bireylere konuyla ilgili bakış açısı sağlamayı amaçlamaktadır.
Dünyada 200'den fazla TTY kullanılmaktadır Complementary and Alternative Medicine (NCCAM) temel olarak bu yöntemlerini beş grupta sinıflandırmaktadır (Tablo 1).

Tablo 1. Tamamlayıcı Tedavi Yöntemleri

\section{1) Zihin-Beden Yöntemleri}

Bedensel fonksiyonları geliştirecek ve iyileştirecek zihinsel becerinin ortaya çıkarılması esasına dayanır.

\section{2) Alternatif Medikal Yöntemler}

Vücudun kendi içinde var olduğu düşünülen iyileşme gücünün ortaya çıkarılması esasına dayanır.
Müzik, sanat terapisi, hipnoz, yoga, biyolojik geri bildirim, meditasyon, dua, mental iyileşme, odaklanma, hayal kurma...

\section{3) Biyolojik Temelli Tedavi Yöntemler}

Homeopati, naturapati, ayurveda, akupunktur, TENS (Traskütan Elektriksel Sinir Stimülasyonu), intradermal su enjeksiyonu...

\section{4) Manipülatif ve Beden Temelli Yöntemler} Bedenin manipüle veya hareket ettirilmesidir. Çeşitli masaj tekniklerini içerir.

5) Enerji Tedavi Yöntemleri Biyoenerji ve manyetik enerji alanını kullanır.
Bitkiler (fitoterapi, aromaterapi), yiyecekler, özel diyetler, vitaminler...

Masaj, refleksoloji, hidroterapi, akupressure, şiropraktik...

Terapötik dokunma, reiki, elektromanyetik alan kullanma, biyoenerji...

(Turan, Öztürk ve Kaya 2010; Set 2011; Ertem ve Sevil 2005; Tournaire and Theau-Yonneau 2007)

\section{Doğum Ağrisında \\ Tamamlayıcı Tedavi Yöntemleri}

Literatürde doğum ağrısı kontrol yöntemleri için basitlik, güvenilirlik ve fetal hemostazın koruması özellikleri aranmaktadır. Doğum ağrısının yönetiminde uygulanacak yöntemler ağrının azaltılmasını ve kadının doğumdan memnuniyetini de artırmalıdır. TTY bu özellikleri desteklemektedir (Karabulutlu 2014). Ayrica TTY'i, hem kadinlar hem de sağlık çalışanları aşağıdaki nedenlerden dolayı doğum ağrısının yönetiminde medikal yöntemlere oranla daha çok tercih etmektedirler.

- TTY invaziv değildir, uygulaması kolay ve güvenilirdir.

- Gebenin ve çevresindeki destek veren kişilerin aktif olarak eyleme katılmasına olanak sağlarlar. Maliyeti azaltmada etkindirler.

- Anne ve fetüs sağlığı açısından zararsizdirlar.

- Yan etki ya da alerji riskleri yoktur.

- Algilanan doğum ağrısını azaltarak gebenin anksiyete düzeyini düşürürler

- Annenin doğumda daha olumlu deneyimler yaşamasını sağlarlar.

- Uterin kan akımını artırırlar.
- Kas gerilimini azaltırlar.

- Doğum eylemini yavaşlatmazlar.

- Anne-bebek ilişkisinin kurulmasını desteklerler.

- Eşler arasında yakınlığı pekiştirirler (Brown, Douglas and Flood 2001;Ertem ve Sevil 2005)

Doğum ağrısını gidermek amaciyla en sık kullanılan TTY ise şunlardır:

\section{Müzik}

Müzik, belirli ritm ve melodi gibi organize bileşenleri içeren işitsel bir uyarandır. Müzik terapisi; stres, ağrı, kayg1 ve izolasyonun azaltılmasıyla bir davranış değişikliği yaratma ve duygu durumunu değiştirmeyi, yaşam kalitesini geliştirmeyi, kendini ifade etme kabiliyetini artırmayı, rahatlamayı öğretmeyi, baş etme stratejilerine yardımc1 olmayı ve normal bir çevre sağlamayı hedefler (Yıldırım ve Gürkan 2007). Farklı müzik türlerinin eylemdeki gebelerin ağrı ve anksiyete düzeylerinde olumlu düşüş sağladığı, eylemin seyrini hızlandırdığ1, ağn toleransını, destek ve güçlülük durumunu, ritmik olarak nefes almay1, hareket etme durumunu artırdığı bilinmektedir (Tournaire and Theau-Yonneau 2007; Simkin and Boldig 2004). Doğu kültüründe Rehavi makamındaki müziğin ikindiyle yats1 arası ve seher zamanı etkili olduğu bilinir. Özellikle doğum ağrısına yardımcı olan bu makam içerdiği ney sesi ile 
kadında huzur ve rahatlama duygusu yaratarak ağrının giderilmesinde, ayrıca ruhsal durumun tedavisinde de faydalı olabilmektedir ( Mamuk ve Davas 2010).

\section{Hipnoz}

Hipnoz uygulaması doğumda ağrıyı ve endişeyi azaltmak ya da ortadan kaldırmak için Amerikan Tıp Birliği tarafından kabul edilen bir yöntemdir. Hipnoz derin konsantrasyon gerektiren farklı bir bilinç durumudur. İyi hipnoz olabilen bir kadın farkındalığını kaybetmeden doğum ağrısını tam kontrolü altına alabilir. Ağrı ortadan kalkmaz ancak kadının ağrı algılamasında değişiklik olur. Kadın ağrıyı hisseder fakat canı yanmaz. Kadın kontraksiyonlar arasındaki dinlenme süresini olduğundan daha uzun ve ağrılı bir periyodu olduğundan daha kisa hisseder (Şenel 2005). Hipnozun doğumun ilk evresini kısalttığ 1 , daha iyi analjezi sağladığı, doğumu hoş ve doyum verici bir tecrübe haline getirdiği, doğum süresince korkuyu, gerilimi ve ağrıyı azalttığı ve ağr1 eşiğini arttırdığı da belirtilmektedir ( Roberts, Raynes-Greenow, Nassar, Trevena and McCaffery 2004). Ayrıca doğum ağrısının azaltılması konusunda etkin ve diğerlerine oranla farmakolojik ajan ve ekipman gerektirmemesi, fetüs ve yenidoğan üzerinde olumsuz etkilere sahip olmaması gibi avantajları da vardır. Bu avantajlara rağmen yaygın bir şekilde uygulanmamasının nedeni ise; gebeliğin son aylarında anne adayı ile birlikte eğitim toplantıları gerektirmesi, hipnozun yapılabilmesi için bu konuda uzman bir kişiye gereksinim olması ve bazı uygulamalar da etkin sonuç alınamamasıdır (Smith, Collins, Cyna and Crowther 2010; Tournaire and Theau-Yonneau 2007; Kömürcü ve Berkiten Ergin 2008; Jones, Othman, Dowswell, Alfirevic, Gates, Newburn et. al. 2012; Tiran 2009).

\section{Yoga}

Yoga kökeni Hindistana dayanan çok eskiden beri kullanılan bir zihin-beden uygulamasıdır. Kelime anlamı olarak "bedenin, zihin ve ruh bütünleşmesi” demektir. Yoganın amacı vücut mekaniklerini, solunum tekniklerini, zihin kontrolünü, meditasyonu ve tefekkür uygulamalarını kullanarak duygusal, zihinsel, bedensel ve ruhsal boyutta denge yaratmaktadir (Curtis, Weinrib and Katz 2012). Fiziksel gücü koruyarak, artırarak ve esnekliği sağlayarak doğumda annenin enerjisinin ve dayanıklılığının artmasını sağlar. Gebeliğe bağlı duruş bozuklukları en aza indirir. Solunum ve dolaşım sistemi ile karın kasları güçlenir bu sayede gebe doğum sırasında kontraksiyonları ve solunum kaslarını etkin kullanır. Gebenin gerginlik ve dengesizlik alanlarını belirleyerek vücut farkındalığı öğretir ve doğum sırasında ağrının yapmış olduğu rahatsızlığı gidermek için esneklik ve dinlenme yeteneğini artırır. Doğumun kolay ve hızlı olmasını sağlar. Bedensel ve zihinsel gerginlikten uzaklaştırır. Gebenin stresini, öfkesini azaltır daha sakin ve daha kontrollü daha huzurlu olmasını sağlar. Doğum sonrasında da annenin bebeği kabullenme sürecini hızlandırır (Curtis, Weinrib and Katz 2012; Wren, Wright, Carson and Keefe 2011).

\section{Homeopati}

Homeopati Yunanca'dan gelen "homoios" (benzer) ve "pathos" (hastalıktan acı çekmek) kelimelerinden oluşmaktadır. Temel prensip, "benzeri benzerle tedavi" etmektir. Sağllklı bir bireyde herhangi bir hastalık meydana getirerek, hastalık bulguları ortaya çıkartan doğal bir maddenin, aynı bulguları taşıyan sağlıksız bireye belli yöntemlerle sulandırılarak ve gücü artırılarak verilmesi sonucu bireyin sağlığına kavuşturulması prensibine dayanır. Yani daha basit olarak, bir madde sağlıklı bir kişide hastalık belirtileri oluştururken, aynı hastalık belirtilerini gösteren bir hasta o maddeyle tedavi edilebilir. Örneğin "sağlıklı bir insana tekrarlayan dozlarda verildiğinde beden isısında yükselmeye yol açan Aconitum, soğuk havaya maruz kalan yüksek ateşli bir hastada ateşi düşürebilmektedir" (Turan, Öztürk ve Kaya 2010; Jones, Othman, Dowswell, Alfirevic, Gates, Newburn et. al. 2012; Bulduklu 2015).Doğru dozda ve doğru yolla uygulanan homeopatikler gebe doğum sırasında aşırı bel ağrısı yaşadığında, ilerlemeyen doğum eyleminde ve annenin çok bitkin olduğu durumlarda kullanılmaktadır (Smith, Collins, Cyna and Crowther 2010).

\section{Şiropraktik}

Şiropraktik (chiropractic) kelimesi Yunanca "chiros" (el) ve "practicos" (uygulama) kelimelerinden gelmekte ve elle yapilan uygulama anlamını taşımaktadır. Şiropraksi, kas, eklem, kemik, tendon, kıkırdak ve ligamentlerin yer aldığ bağ dokularının ve kas iskelet sistemi rahatsızlıklarının giderilmesinde kullanılan hareketlerdir (Turan, Öztürk ve Kaya 2010). Şiropraktik uygulaması gebelik ve doğum sırasında bel ağrısını hafifletmede, sik karşı1laşılan kas-iskelet problemlerinin giderilmesinde ve bebeğin doğumunun çok daha kolay olmasında etkili olmaktadır. Ayrıca şiropraktik uygulaması doğum sırasında hem 
vakum, forseps ve sezeryan uygulamalarına gereksinimi azaltmakta hem de vakum ve forseps uygulamalarına bağlı oluşabilecek servikalspinal kord yaralanmalarını engellemektedir (Borggren 2007).

\section{Akupunktur}

Akupunktur, dünyanın en eski tedavi uygulamaları arasında yer almaktadır. Binlerce yıldır Çin ve diğer Asya ülkelerinde uygulanmaktadır. Akupunktur kelimesi Latince "acus" (iğne) ve "pungere" (delmek) anlamına gelmektedir. Geleneksel Çin tıbbının bir parçası olan akupunkturda; vücudun özel noktalarında cilde yerleştirilen ince metal iğneler aracılı̆̆ 1 ile stimülasyon sağlanarak, derinin hemen altından geçen enerji kanalları ve bu kanallar üzerinde bulunan direnç noktalarının ilintili bulunduğu organlar arasında ilişki sağlanmaktadır (Smith, Collins, Cyna and Crowther 2010; Tournaire and Theau-Yonneau 2007; Kömürcü ve Berkiten Ergin 2008; Tiran 2009 ). Akupunkturun amac1, vücudun tekrar uyum ve dengeye ulaşmasını sağlamaktır. $\mathrm{Bu}$ denge ve uyumun meydana gelmesinde ise akupunktur uygulamasinin analjezik, homeostatik, otoimmun, sedatif, psikolojik ve motor fonksiyon iyileştirici etkilerinden yararlanılmaktadır (Horasanl1, Usta ve Yeşilay 2008).

Çin'de 5000 yıldan bu yana akupunktur, doğum ağrısını azaltmak amacı ile kullanılmaktadır. Doğum ağrısını azaltmak amaciyla el, ayak ve kulaktaki akupunktur noktaları kullanılmaktadır. Akupunktur ile uyarılan bu bölgeler tüm vücut üzerinde genel analjezik etki gösterirler ve kasılmaları tetiklerler. İşleme başladıktan 20 dakika sonra kadin kendini rahat ve sakin hisseder (Smith, Collins, Cyna and Crowther 2010; Tournaire and Theau-Yonneau 2007; Kömürcü ve Berkiten Ergin 2008; Tiran 2009; Hsieh, Kuo, Yen and Chen 2004). Yapilan çalışmalarda akupunkturun meperidin, epidural anestezi ve doğum indüksiyonu kullanım ihtiyacını azalttı̆̆ 1 , doğum ağrısını azalttığ memnuniyeti artırdığı belirtilmiştir (Şenel 2005)

TENS

TENS, rahatlamayı sağlamak ya da zihinden ağrıyı çıkarabilmek için, elektrik uyarılarını spesifik sinirlere ileten televizyon kumandası boyutunda bir araçtır. Cilde yerleştirilen elektrotlarla sinir sistemine kontrollü, düşük voltajlı elektrik akımı uygulanması esasına dayanır. Akut ve kronik ağrılarda çok geniş kullanımı vardır. Sırtta dört noktaya uygulanan TENS'in analjezik tüketimini belirgin olarak azalttığ 1 ve doğumun birinci evresinde çok etkili olduğu gösterilmiştir (Smith, Collins, Cyna and Crowther 2010; Tournaire and Theau-Yonneau 2007; Kömürcü ve Berkiten Ergin 2008; Camann and Alexander 2008; Tiran 2009; Jones, Othman, Dowswell, Alfirevic, Gates, Newburn et. al. 2012).

\section{Masaj}

İyileşme ve sağlığı destekleme amacıyla yumuşak dokunun değişik tekniklerle manipülasyonudur. Masaj, zihni ve kasları gevşeterek ağrı eşiğini yükseltmektedir. Birçok masaj tekniği bulunmaktadır. En sık kullanılan teknik, hafif basıncın kullanıldığ İsveç Masajıdır (Hsieh, Kuo, Yen and Chen 2004). Masaj, özellikle ebe/hemşireler tarafından, ağr1 gidermede ve hastanın rahatlatılmasinda yıllardır kullanılmaktadır. Doğum sırasında ise gevşemeyi sağlamak, ağrı ve acı çekmeyi azaltmak, doğum sürecini kısaltmak ve kadının doğum ağrısı ile baş etme yetisini artırmak için kullanılır. Aromaterapi yağları ya da losyonları kullanılarak masaj yapmak hem kontraksiyon sirasinda hem de kontraksiyonlar arasında gevşeme ve rahatlamayı sağlamaktadır. (Smith, Collins, Cyna and Crowther 2010; Chang, Wang and Chen 2002; Jones, Othman, Dowswell, Alfirevic, Gates, Newburn et. al. 2012)

\section{Refleksoloji}

Refleksoloji, sinir noktalarının belirli tekniklerle uyarılması sonucu ortaya elektrokimyasal mesajlar çıkaran bir uygulamadır. $\mathrm{Bu}$ uygulama ile, nöronların yardımıyla ilgili organlar uyarılarak, fiziksel problemlerle ilgili gerginlik ve stresi azaltılır ve vücudun dengede kalması sağlanır. Doğumda refleksoloji uygulaması eylemin I. evresinde, her iki ayağın solar pleksus, beyin- omirilik, dalak, troid, barsak ve uterus-vajina-over refleks noktalarına yapılır. Doğum sırasında uterus kasılmalarını teşvik etmek için oksitosin salınımının uyarılmasında, doğum sırasındaki kasılmaların düzenlenmesinde, kasilmalar sirasinda gevşemenin oluşmasında, deneyimlenen ağrı düzeyinin azaltılmasında ve doğumun süresinin kısalmasında etkilidir. (Valiani, Shiran, Kianpour and Hasanpour 2010; Dolation, Hasanpour, Montazeri, Heshmat and Alavi Majd 2011; Öztürk ve Sevil 2013)

\section{Hidroterapi}

Başlica hidroterapi yöntemleri vücudun tamamına veya bir kısmına uygulanan; oturma banyoları, buhar banyoları, kolon irrigasyonu, sicak/soğuk kompres ve buz uygulamalarıdır. Doğum sırasında hidroterapi kullanımının avantajları; ağrıyla başa çıkmada farmakolojik 
yöntemlerin kullanımının azaltılması, gevşemeyi artırmas1, doğum ağrısını azaltması, doğum eylemini hızlandırması, annede doğum eylemini kontrol edebilme duygusunu yükseltmesi, doğum kanalı ve perinenin elastikiyetini artırmas1, yırtıkların şiddetini, insidansını ve epizyotomiye duyulan gereksinimi azaltmasıdır (Kömürcü ve Berkiten Ergin 2008; Karagülle 2008).

\section{Akupressure}

Parmaklarla veya küçük boncuklarla akupunktur noktalarına basınç uygulayarak, kan dolaşımı gibi enerji kanallarının düzgün çalışmasını sağlayan bir tedavi yöntemidir. Bu yöntemle kadının vücudunun enerji ve hormonal kontrolü de düzenlenmektedir. Akupressure doğum eyleminde ağriyı azaltmak ve doğum eyleminin süresini kısaltmak amacıyla kullanılmaktadır. Doğumda güvenilir, etkili, maliyetsiz ve kolay uygulanabilir olduğu için tercih edilmektedir. Doğum eylemi sirasında birçok akupunktur noktası kullanılmaktadır. $\mathrm{Bu}$ noktalara yapılan basınç hipofiz bezini uyararak oksitosin salınımını teşvik ederek, kontraksiyonları uyarmakta ve etkin hale getirmektedir. Doğum ağrısını gidermek ve eylemin ilerlemesi sağlamak amacıyla sıklıkla SP6 noktas1 kullanılmaktadır (Tournaire and Theau-Yonneau 2007; Hsieh, Kuo, Yen and Chen 2004). (ISSE)

İntradermal Steril Su Enjeksiyonu

Uygulama 0.05-0.1 ml steril suyun sakrum çevresinde dört ayrı noktaya enjeksiyonu ile 4 su kabarcığının oluşturulması esasına dayanır (Simkin and Boldig 2004; Y1lar 2014). Steril su sinir uçlarını uyararak daha şiddetli olan diğer ağr1 hislerini bloke eder. ISSE belirgin düzeyde bel ağrısını, minimal düzeyde de abdominal kontraksiyonların yarattı̆̆ ağrıyı azaltmaktadır. Anne ve yenidoğan üzerinde olumsuz bir etkiye sahip değildir. Ebe/hemşireler tarafindan kolaylıkla uygulanabilecek basit bir işlemdir. Doğumdaki uterus kontraksiyonlarına bağlı ağrıda rahatlama sağlamaması ya da çok az sağlaması ve etkisinin kı sürmesi dezavantajıdır (Tournaire and Theau-Yonneau 2007; Lee, Coxeter, Beckmann, Webster, Wright, Smith et. al. 2011; Camann and Alexander 2008). ISSE uygulamasının doğum eyleminde bel ağrısının azaltılması amacıyla kullanılan bir yöntemdir. Bunun yanında doğum eylemi sirasında fetal rotasyon, pelvik taban kasları ve servikal dilatasyon üzerine olumlu etkisi vardır. (Lee, Coxeter, Beckmann, Webster,
Wright, Smith et. al. 2011; Camann and Alexander 2008; Y1lar 2014).

\section{Beslenme Tedavileri}

Sağlığın sürdürülmesi, hastalığın önlenmesi, yaşam süresinin uzatılması, enerjinin artırılması, kilo kontrolü ya da özel sağlık sorunlarının ortadan kaldırılması amacıyla çeşitli beslenme şekilleri kullanılır. Kalsiyum ve magnezyum ağrının tedavisinde en s1k önerilen iki minerallerdir. Özellikle artrit ve osreoporozda tavsiye edilirler. Ağrıya bağlı semptomların giderilmesinde tamamlayıcı tedavide esansiyel yağ asitleri de kullanılmaktadır. Bunlar içerisinde özellikle gama-linolenik asitin (omega-6) ve balıktan türetilmiş eikosapentaenoik asitin (omega-3) ve glukozamin sülfatın kullanımı tercih edilmektedir (Turan, Öztürk ve Kaya 2010). Kordi ve arkadaşlarının aktardığına göre, beslenme tedavileri uterus adelesini güçlendirerek, oksitosin hormon salgısını artırarak ve servikal olgunlaşmayı hızlandırarak doğumun daha az ağrılı ve daha kolay olmasını sağlamaktadır. (Kordi, Aghaei Meybodi, Tara, Nemati and Shakeri 2014).

\section{Terapötik Dokunma ve Reiki}

Enerji terapileri olarak adlandırilan terapötik dokunma ve reiki insan vücudunun enerji merkezlerine elle dokunarak vücutta var olan enerji yetersizliklerini ve tıkanıklarını gideren bir şifa tekniğidir. Eller; baş, boyun, göğüs, karın boşluğu, kasıklara dokunmak suretiyle her bir pozisyonda 3-5 dakika tutulur. Problemli bölgelerde bu süre 10-20 dakikaya uzayabilir. Tedavi süresi ortalama 30-90 dakika sürer. Terapötik dokunma ve reiki; astım, hipertansiyon, kanser, yorgunluk, artrit, akut ağrı, kronik ağrı, stres, depresyon ve anksiyete gibi birçok sağlık probleminde kullanılır (Sağkal ve Eşer 2011). Doğumda terapotik dokunmanın amacı bakımda iletişim ve güveni sağlamaktır. Uterusun ağrılı kontraksiyonları, kadınların sırtlarına, karınlarına, kalçalarına, uyluklarına, sakrum ve perine bölgelerine ellerle basınç uygulanarak hafifletilir (Tournaire and TheauYonneau 2007).

\section{Fitoterapi (Bitkisel Tedaviler)}

Fitoterapi, "tıbbî bitkilerle tedavi" anlamına gelmektedir. Hastalıkların, tedavi edici değere sahip taze veya kurutulmuş bitki kısımları ya da bunlardan elde edilen ekstraksiyon ürünleri kullanılarak üretilen çay, damla, draje, kapsül, şurup, tablet ile tedavi edilmesi anlamındadır (Kömürcü ve Berkiten Ergin 2008). Anadolu halk kültüründe; "Meryem Ana Eli" denen bitkinin içine konduğu sudan içmenin doğumu 
kolaylaştırdığına inanılmaktadır. Üzüm, badem, ayva yedirilmesinin doğum sırasında gebeye enerji verdiği, sıcak pekmezli kavrulmuş susam, karanfil, defne tohumu, bal karışımlı macun, sarımsak ve nane karışımı, hemşe otu, ısırgan otu, manda yoğurdu yedirme ya da vajene yumurta akı sürme gibi uygulamaların ise doğumu yardımcı olduğu belirtilmektedir. Koçak ve arkadaşlarının aktardığına göre Tayland'da yeşil sebzenin ve özel bitki çaylarının üç gün süre ile içilmesinin, doğumu kolaylaștırdığına inanılmaktadır (Koçak, Can ve Soğukpınar 2010).

\section{Aromaterapi}

Aromaterapi, "tedavi edici" özelliklerini kullanabilmek için bitkilerden damitılan yüksek konsantrasyonlu öz yağların ve kokuların kullanılmasıdır. Esansiyel yağların vücutta yatıştırıcı, uyarıcı ve rahatlatıcı etki gösteren nörotransmitterlerin (asetilkolin, dopamin, seratonin vd.) salgılanmasını artırdığı düşünülmektedir. Yağlar deriye masaj yöntemiyle, inhalasyon ve yağların yanmas1 sonucu oluşan kokunun solunması şeklinde uygulanmaktadır. Doğum sırasında aromaterapi uygulamas1; gül, lavanta, neroli, adaçayı vb. esansiyel yağlarının travaydaki annenin cildine sürülmesini içerir. Bebeğin inişi ve doğumunun gerçekleştiği ikinci evrede nane yağının güç hissi verdiği, lavanta yağının panik duygusunu azalttığı ve kontraksiyonları güçlendirdiği,

\section{KAYNAKLAR}

Borggren CL. Pregnancy and Chiropractic: A Narrative Review of the Literature. Journal of Chiropractic Medicine2007;6(2):70-74.

Brown TS, Douglas C, Flood PL. Women's Evaluation of Intrapartum Nonpharmacological Pain Relief Methods Used During Labor. The Journal of Perinatal Education 2001;10(3):1-8.

Bulduklu Y. Hedef Kitle Bağlamında Tamamlayıcı ve Alternatif Tip Uygulamaları. Türkiyat Araştırmaları Dergisi 2015;37:607-27.

Camann W, Alexander KJ. Kolay Doğum. Günaydın B, editör. 1. Baskı. Ankara: İlke Yayınevi; 2008.p.203-10.

Chang M, Wang S, Chen C. Effects of Massage on Pain and Anxiety During Labour: A Randomized Controlled Trial in Taiwan. Journal of Advanced Nursing 2002;38(1):68-73.

Curtis K, Weinrib A, Katz J. Systematic Review of Yoga for Pregnant Women: Current Status and Future Directions. Evidence-Based Complementary and Alternative Medicine 2012;1-13.

Dolation M, Hasanpour A, Montazeri Sh, Heshmat R, Alavi Majd H. The Effect of Reflexology on Pain Intensity and Duration of Labor on Primiparas. yasemin yağının analjezik ve antispazmotik etkiye sahip olduğu bilinmektedir (Smith, Collins, Cyna and Crowther 2010; Tournaire and Theau-Yonneau 2007; Kömürcü ve Berkiten Ergin 2008; Camann and Alexander 2008; Tiran 2009; Jones, Othman, Dowswell, Alfirevic, Gates, Newburn et. al. 2012).

\section{SONUÇ VE ÖNERILER}

Sonuç olarak, doğum ağrısı kadınlar için önemli bir yaşam deneyimidir. $\mathrm{Bu}$ sürecin en iyi şekilde sonlanması bireyler açısından son derece önemlidir. TTY'de bilimsel tıbba destek amaçlı yapılan tedavilerdir. Gebenin fiziksel ve psikolojik bakım gereksinimlerini karşılamak, gebenin doğum ağrısıyla baş etmesine yardımcı olmak, yasam kalitesini geliştirmek, gebenin işbirliği ve katkılarını sağlayarak doğum eyleminin olabildiğince sorunsuz yaşanması amacıyla uygulanır. Bu nedenle doğum ebesi ve hemşiresi doğum ağrısıyla baş etmede TTY'ni, etkilerini, sinırlılıklarını bilmeli ve bu yöntemlerin etkin bir şekilde uygulanmasında gebeye yardımc1 olmalıdır. Ayrica TTY'nin uygulama alanlarında ebe ve hemşireler tarafindan kullanım oranlarının artırılması ve konu ile ilgili daha geniş popülasyonu ve süreyi kapsayan doğumhanelerde ve gebe eğitim sınıflarında bilimsel çalışmaların yapılması önerilmektedir.

Iranian Red Crescent Medical Journal 2011;13(7): 475-79.

Ertem G, Sevil Ü. Doğum ağrısı ve hemşirelik yaklaşımı. Atatürk Üniversitesi Hemşirelik Yüksekokulu Dergisi, 2005, 8(2): 117-23.

Horasanlı E. Usta B. Yeşilay A. Medikal Akupunktur. Yeni Tıp Dergisi 2008;25(2):70-5.

Hsieh LL, Kuo CH, Yen MF, Chen TH. A Randomized Controlled Clinical Trial for Low Back Pain Treated by Acupressure and Physical Therapy. Preventive Medicine 2004;39(1):168-76.

Jones L, Othman M, Dowswell T, Alfirevic Z, Gates S, Newburn M, et.al. Pain Management for Women in Labour: An Overview of Systematic Reviews (Review). The Cochrane Library 2012;14(3):5-7.

Karabulutlu Ö. Doğum Ağrısı Kontrolünde Kullanılan Nonfarmakolojik Yöntemler. Caucasian Journal of Sciencetley 2014;1(1):43-50.

Karagülle Z. Hidroterapi, SPA, Balneoterapi, Talassoterapi. Türkiye Klinikleri Tıp Bilimleri Dergisi 2008;28(1):224-9.

Koçak Y, Öztürk Can H, Soğukpınar N. Geleneksel Doğum Uygulamaları ve Doğum 
Yardımcıları. e-Journal of New World Sciences Academy Life Sciences 2010;5(4):1-6.

Kordi M, Aghaei Meybodi F, Tara F, Nemati M, Shakeri MT. The Effect of Late-Pregnancy Consumption of Date Fruit on Cervical Ripening in Nulliparous Women. Journal of Midwifery and Reproductive Health. 2014;2(3): 150-6.

Kömürcü N, Berkiten Ergin A. Doğum Ağrısının Kontrolünde Non-Farmakolojik Yöntemler. Kömürcü N, Berkiten Ergin A, editörler. Doğum Ağrısı ve Yönetimi. 1. Baskı. İstanbul: Bedray Yayıncılık; 2008.p.57-143.

Lee $\mathbf{N}$, Coxeter $\mathbf{P}$, Beckmann $M$, Webster J, Wright V, Smith T, et.al. A Randomised NonInferiority Controlled Trial of a Single Versus a Four Intradermal Sterile Water Injection Technique for Relief of Continuous Lower Back Pain During Labour. BMC Pregnancy and Childbirth 2011;11(21):1-9.

Mamuk R, Davas Ní. Doğum Ağrısının Kontrolünde Kullanılan Nonfarmakolojik Gevşeme ve Tensel Uyarılma Yöntemleri. Şişli Etfal Hastanesi Tıp Bülteni 2010;44(3):137-44.

Öztürk R, Sevil Ü. Refleksolojinin Kadın Sağlığ Üzerine Etkisi. Uluslararası Hakemli Akademik Spor Sağlık ve Tıp Bilimleri Dergisi 2013;8(3):87-100.

Roberts CL, Raynes-Greenow CH, Nassar N, Trevena L, McCaffery K. Protocol for a Randomised Controlled Trial of a Decision Aid for the Management of Pain in Labour and Childbirth. BMC Pregnancy Childbirth 2004;4(1):24.

Sağkal T, Eşer İ. Hemşirelikte Yeni Bir Uygulama: Reiki Dokunma Terapisi. Maltepe Üniversitesi Hemşirelik Bilim ve Sanatı Dergisi 2011;4(1):182-9.

Set T. Ağrı ile Baş Etmede Tamamlayıcı ve Alternatif Tedaviler. Türkiye Klinikleri Journal of Family Medicine Special Topics 2011;2(2):79-82.

Simkin P, Boldig A. Update on Nonpharmacologic Approaches to Relieve Labor Pain and Prevent
Suffering. Journal Midwifery Womens Health 2004;49(6):489-504.

Smith CA, Collins CT, Cyna AM, Crowther CA. Complementary and Alternative Therapies for Pain Management in Labour (Review). The Cochrane Collaboration and Published in The Cochrane Library 2010;9(4):1-43.

Şenel AC. Geriatrik Hastalarda Postoperatif Analjezi. Ondokuz Mayıs Üniversitesi Tıp Dergisi 2005;22(1):33-7.

Tiran D. Complementary Therapies in Midfery. In: Fraser DM, Cooper MA, eds. Myles Midwives, $15^{\text {th }}$ ed. New York: Elsevier Publish; 2009. p.959-97.

Tournaire M, Theau-Yonneau A. Complementary and Alternative Approaches to Pain Relief During Labor. Evidence-Based Complementary and Alternative Medicine 2007;4(4):409-17.

Turan N, Öztürk A, Kaya N. Hemşirelikte Yeni Bir Sorumluluk Alanı: Tamamlayıcı Terapi. Maltepe Üniversitesi Hemşirelik Bilim ve Sanatı Dergisi 2010;3(1):94-8.

Valiani M, Shiran E, Kianpour M. and Hasanpour M. Reviewing the Effect of Reflexology on the Pain and Certain Features and Outcomes of the Labor on the Primiparous Women. Iranian Journal of Nursing and Midwifery Research 2010;15(1):302-10.

Wren AA, Wright MA, Carson JW, Keefe FJ. Yoga for Persistent Pain: New Findings and Directions for an Ancient Practice. Pain 2011; 152(3):477-80.

Yılar Z. Doğum Eyleminde Bel Ağrısının Hafifletilmesinde İntradermal Steril Su Enjeksiyonu. Anadolu Hemşirelik ve Sağlık Bilimleri Dergisi 2014;17(3):179-86.

Yıldırım S, Gürkan A. Müziğin, Kemoterapi Yan Etkilerine ve Kayg1 Düzeyine Etkisi. Anadolu Psikiyatri Dergisi 2007;8(1)37-45. 